\title{
FUCHS' HETEROCHROMIC CYCLITIS AND RETINAL VASCULAR ABNORMALITIES IN PROGRESSIVE HEMIFACIAL ATROPHY
}

\author{
ELLEN LA HEY ${ }^{1}$ and G. SEERP BAARSMA ${ }^{2}$ \\ Amsterdam and Rotterdam
}

\begin{abstract}
SUMMARY
We report a case of progressive hemifacial atrophy with a combination of ipsilateral Fuchs' heterochromic cyclitis and retinal vascular abnormalities. Recently, evidence was found for a neurovascular defect in hemifacial atrophy. Our case not only supports the (clinical) association between Fuchs' heterochromic cyclitis and hemifacial atrophy, but the retinal vascular abnormalities found in this patient add further support to the existence of a neurovascular defect. These findings and our short review of the literature point to the hypothesis of a common sympathetic defect, implicated in the aetiology of both Fuchs? heterochromic cyclitis and progressive hemifacial atrophy. It has to be borne in mind, however, that Fuchs' heterochromic cyclitis has been reported in association with other diseases. It seems likely that although Fuchs' heterochromic cyclitis is a single clinical entity, it may have more than one cause.
\end{abstract}

Hemifacial atrophy (Parry-Romberg syndrome) was first described by Parry in $1825 .{ }^{\prime}$ A more detailed description of this syndrome was made by Romberg in 1846, who distinguished it from the congenital non-progressive form of this disorder. ${ }^{2}$ Hemifacial atrophy is a rare condition of unknown aetiology, characterised by a slowly progressive atrophy of one side of the face, primarily involving skin, subcutaneous fat and muscles. The onset of the disease usually occurs in the first two decades of life. If the onset is before the age of 10 years, the borne is also involved, resulting in a severe facial deformity. ${ }^{3}$ In $7 \%$ of cases the ipsilateral limbs and trunk are involved and occasionally the syndrome is bilateral. ${ }^{4-6}$ Females are more often affected than males in a ratio of $3: 2 .{ }^{4}$ Progression of the disease occurs more rapidly in the first 2-10 years after onset and it may stabilise at any age. ${ }^{7}$

From: 'Department of Ophthalmo-Immunology, The Netherlands Opthalmic Research Institute, Amsterdam; ${ }^{2}$ Eye Hospital, Rotterdam, The Netherlands.

Correspondence to: Ellen La Hey, MD, Department of OphthalmoImmunology, The Netherlands Ophthalmic Research Institute, PO Box 12141, 1100 AC, Amsterdam, The Netherlands.
Many hypotheses have been put forward to explain the aetiology of progressive hemifacial atrophy, which is still unknown. A relationship with either localised scleroderma, trauma, infection, an autoimmune disorder, a trigeminal neurovasculitis, heredodegenerative factors or a defect of the sympathetic nervous system have been suggested as possible causes. ${ }^{3.5,6.8 .9}$ Ocular involvement in hemifacial atrophy occurs in up to $40 \%$ of cases..$^{10}$ Most of the ophthalmologic conditions appearing in hemifacial atrophy have been described in single case reports.

We describe a patient with progressive hemifacial atrophy who developed the clinical features typical of Fuchs' heterochromic cyclitis. In addition, ipsilateral retinal vascular abnormalities were present in the fundus of this same patient. This combination has not been reported before in the literature. Our case not only supports the association between Fuchs' heterochromic cyclitis and hemifacial atrophy, but the retinal vascular abnormalities found in this patient add further support to recent evidence of a neurovascular defect in progressive hemifacial atrophy.

\section{CASE REPORT}

A 28-year-old Caucasian woman with a previous diagnosis of right-sided progressive hemifacial atrophy was referred to us several years ago because of visual complaints in the right eye. The process of facial atrophy had started when she was 19 years old. Because of this late onset there was no bone involvement and only slight cartilage involvement. The skin, subcutaneous fat and muscles, however, were severely affected and an obvious facial asymmetry was visible (Fig. 1). On examination an enophthalmos and thinning of the eyebrow were noted on the right side. Best visual acuity was $10 / 20$ for the right eye and 20/20 for the left eye. The pupil of the right eye was larger and it showed a delayed pupillary reaction to light. In the right eye small translucent keratic precipitates scattered over the entire endothelium and minimal aqueous flare and cells were seen. Diffuse iris atrophy and heterochromia were noted. No posterior synechiae were 


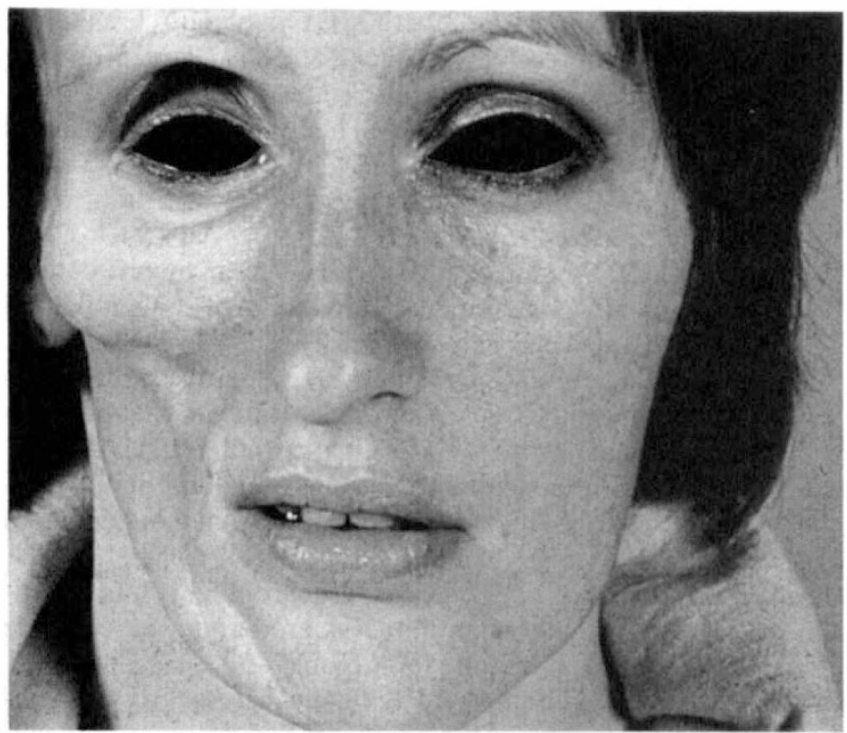

Fig. 1. Conspicuous facial asymmetry in a patient with rightsided progressive hemifacial atrophy, Fuchs' heterochromic cyclitis and retinal vascular abnormalities of the right eye.

present. The lens was clear and in the anterior vitreous fine dust-like opacities were present. On the basis of these characteristic findings the diagnosis of Fuch's heterochromic cyclitis was made. On fundus examination a haemorrhage above the macula along the superotemporal artery and exudates in the upper nasal quadrant of the macula were seen (Fig. 2). Fluorescein angiographic studies revealed the presence of macroaneurysms of the superotemporal artery with leakage in the direction of the macula (Fig. 3). Laser coagulation was performed to decrease this leakage. In the 3 years that followed the keratic precipitates and minimal aqueous chamber reaction remained unaltered. The haemorrhages and exudates diminished after repeated laser coagulation.

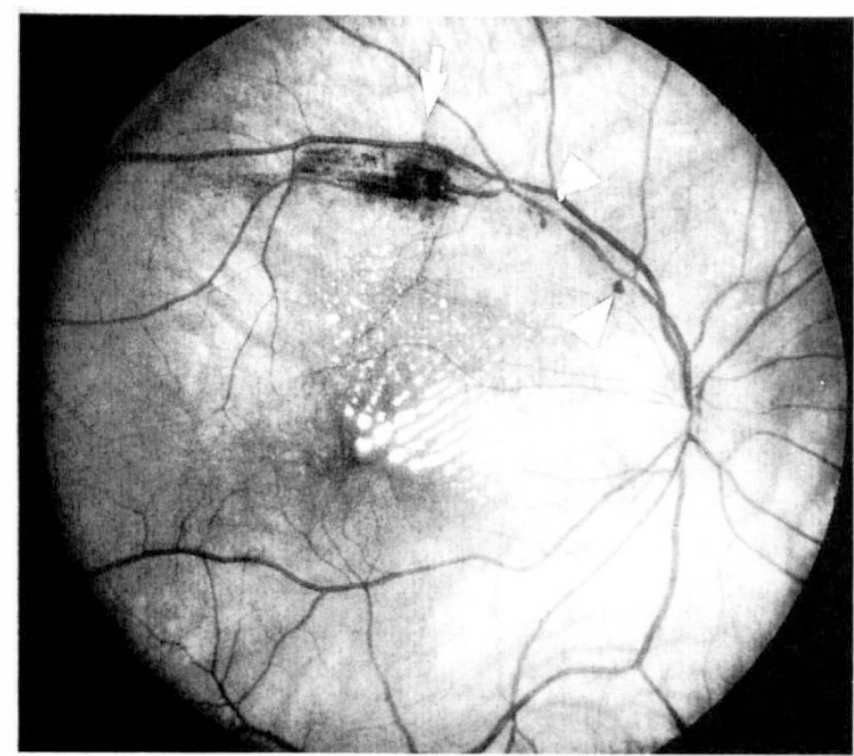

Fig. 2. Fundus photograph of the right eye showing haemorrhage (arrow) and macroaneurysms (arrowheads) along the superotemporal artery, and exudates in the upper nasal quadrant of the macula.

\section{DISCUSSION}

The combination of Fuchs' heterochromic cyclitis and retinal vascular abnormalities as found in our patient has, to our knowledge, not been reported before in hemifacial atrophy. Recently Gass et al. ${ }^{11}$ were the first to describe four cases of hemifacial atrophy with similar retinal vascular abnormalities. In one of their patients a mild cellular reaction in the anterior chamber and vitreous was noted. A second patient had segmental atrophy of the iris. No other anterior segment abnormalities were described. In our patient, however, in addition to the retinal vascular defects, anterior segment findings typical of Fuchs' heterochromic cyclitis were found: small translucent keratic precipitates scattered over the entire endothelium, minimal aqueous flare and cells, diffuse iris atrophy, discrete heterochromia, fine opacities in the anterior vitreous and no posterior synechiae. Complicated cataract or glaucoma had not (yet) developed.

Fuchs' heterochromic cyclitis was first considered to be associated with hemifacial atrophy because both diseases were said to be part of the status dysraphicus. ${ }^{12}$ Sugar and Banks ${ }^{13}$ reviewed the 13 cases of Fuchs' heterochromic cyclitis in hemifacial atrophy reported since 1913 and added another case from their own practice. They suggested that both diseases may result from neurovascular or neurotrophic changes, caused by disturbances of the sympathetic nervous system. Loewenfeld and Thompson ${ }^{14}$ objected that the majority of descriptions of Fuchs' heterochromic cyclitis found in cases with hemifacial atrophy were not typical: there were unusual (pigmented) corneal precipitates, there was no iris atrophy or heterochromia, and in some cases posterior synechiae were found. In our patient, however, the typical features of Fuchs' heterochromic cyclitis were present, as mentioned above. Despite the arguments put forward by Loewenfeld and Thompson ${ }^{14}$ in their extensive review to reject the association between Fuchs' heterochromic cyclitis and hemifacial atrophy, and the hypothesis of a sympathetic

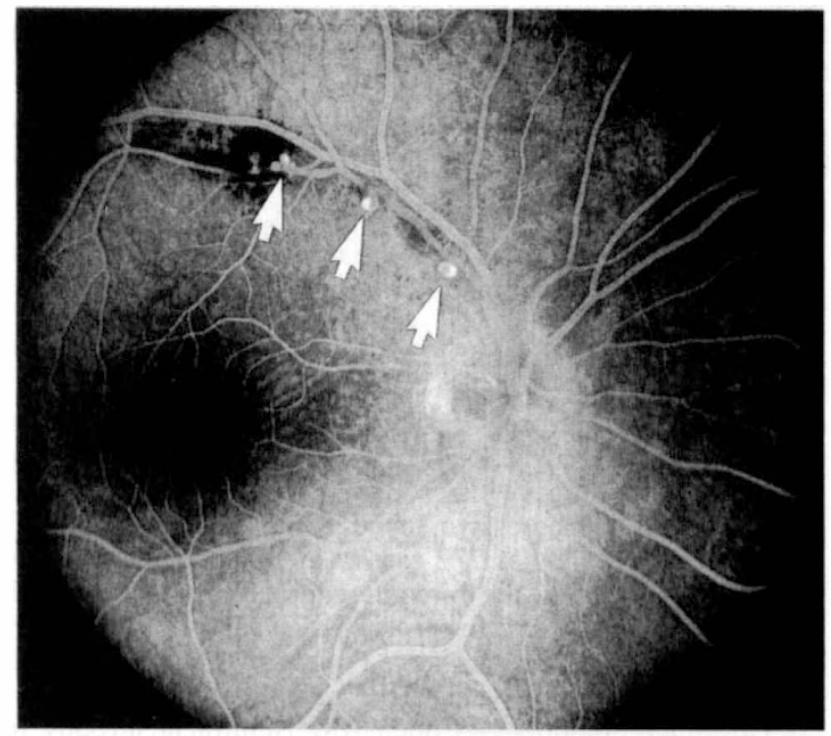

Fig. 3. Fluorescein angiogram of the right eye showing macroaneurysms (arrows) of the superotemporal artery. 
defect implicated in the aetiology of both diseases, many authors ${ }^{15-21}$ still support this theory put forward by Sugar and Banks. ${ }^{13}$

Moss and Cirkelair ${ }^{15}$ provided evidence for this sympathetic hypothesis by demonstrating hemifacial atrophy after unilateral sympathectomy in young rats. Pupillary changes, Horner's syndrome and heterochromia are often reported in patients with hemifacial atrophy, and are all signs of an impaired sympathetic nervous system. ${ }^{16}$

In 1953 a case was described in which Horner's syndrome and Fuchs' heterochromic cyclitis developed consecutively in the same eye after a stellate ganglionectomy. ${ }^{17}$ Recently, five patients with unilateral Fuchs' heterochromic cyclitis and ipsilateral Horner's syndrome were reported..$^{18}$ Electron microscopic studies on Fuchs' heterochromic cyclitis have suggested that the hypochromia may result from a defective melanin production due to abnormal adrenergic innervation..$^{19}$ Furthermore, it has been postulated that the vascular leakage seen in the iris fluorescein angiographic studies on Fuchs' heterochromic cyclitis may be caused by a disturbance in the iris vessel innervation, which is derived solely from the sympathetic nervous system..$^{20,21}$

In a recent electron microscopic study evidence was found for a neurovascular defect involved in the pathogenesis of hemifacial atrophy. ${ }^{3}$ The retinal vascular abnormalities seen in our patient and in those of Gass et al. ${ }^{11}$ may result from such a neurovascular defect. These findings and the above mentioned studies point to the hypothesis of a common sympathetic defect implicated in the aetiology of hemifacial atrophy and Fuchs' heterochromic cyclitis.

In addition to hemifacial atrophy, Fuchs' heterochromic cyclitis has been reported in association with other conditions: ocular toxoplasmosis, ${ }^{22.23}$ ocular trauma, ${ }^{24}$ retinitis pigmentosa ${ }^{25}$ and the subclavian steal syndrome. ${ }^{26}$ Moreover, recent immunohistochemical studies on iris biopsy specimens ${ }^{27,28}$ have failed to show any specific abnormalities in these patients. It is therefore conceivable that although Fuchs' heterochromic cyclitis is a single clinical entity, it may have more than one cause.

Key words: Fuchs' heterochromic cyclitis, Hemifacial atrophy, Retinal vascular abnormalities.

\section{REFERENCES}

1. Parry $\mathrm{CH}$. Collections from the unpublished medical writings of the late Caleb Hillier Parry. London: Underwoods, 1825:478-80.

2. Romberg HM. In klinische Ergebnisse. Berlin: Forstner, 1846:75-81.

3. Pensler JM, Murphy GF, Mulliken JB. Clinical and ultrastructural studies of Romberg's hemifacial atrophy. Plast Reconstruct Surg 1990;85:669-74.

4. Rogers BO. Progressive facial hemiatrophy (Romberg's disease): a review of 772 cases. In: Broadbent TR, editor. Transactions of the the third international congress of plastic surgery. Amsterdam: Excerpta Medica, 1964:681-9.

5. Archambault L, Fromm NK. Progressive facial hemiatrophy. Arch Neurol Psychiatr 1932;27:529-84.

6. Gorlin RJ, Pindborg JJ, Cohen MM. Hemifacial atrophy. In: Gorlin RJ, Pindborg JJ, Cohen MM, editor. Syndromes of the head and neck. New York: McGraw-Hill, 1976:546-52.
7. Miller MT, Sloane H, Goldberg MF, Grisolano J, Frenkel M, Mafee MF. Progressive hemifacial atrophy (Parry Romberg disease). J Pediatr Ophthalmol Strabismus 1987;24:27-36.

8. Wartenberg R. Progressive facial hemiatrophy. Arch Neurol Psychiatr 1945;54:75-96.

9. Hickman JW, Sheils WS. Progressive facial hemiatrophy. Arch Intern Med 1964;113:716-20.

10. Muchnick RS, Aston SJ, Rees TD. Ocular manifestations and treatment of hemifacial atrophy. Am J Ophthalmol 1979;88:889-97.

11. Gass JDM, Harbin TS, Del Piero EJ. Exudative stellate neuroretinopathy and Coat's syndrome in patients with progressive hemifacial atrophy. Eur J Ophthalmol 1991;1:2-10.

12. Passow A. Hornersyndrom, Hetrochromie und Status Dysraphicus: ein Symptomenkomplex. Arch Augenheilkd 1933;197:1-51.

13. Sugar HS, Banks TL. Fuchs' heterochromic cyclitis associated with facial hemiatrophy (sklerodermie en coup de sabre). Am J Ophthalmol 1964;57:627-32.

14. Loewenfeld IE, Thompson HS. Fuchs' heterochromic cyclitis: a critical review of the literature. II. Etiology and mechanisms. Surv Ophthalmol 1973;18:2-61.

15. Moss ML, Cirkelair GJ. Progressive facial hemiatrophy following cervical sympathectomy in the rat. Arch Oral Biol $1960 ; 1: 254-8$.

16. Hoang-Xuan T, Foster S, Jakobiec FA, Tauber J, de la Maza MS, Krebs W. Romberg's progressive hemifacial atrophy: an association with scleral melting. Cornea 1991;10:361-6.

17. Calmettes ML, Deodati R, Amalric P: Un cas d'association d'heterochromie de Fuchs' et de syndrome de Claude Bernard Horner. Rev Oto-Neuro-Ophthalmol 1953;25: $399-400$.

18. Regenbogen LS, Naveh-Floman N. Glaucoma in Fuchs' heterochromic cyclitis associated with congenital Horner's syndrome. Br J Ophthalmol 1987;71:844-9.

19. Melamed S, Lahav M, Sandbank U, Yassur Y, Ben-Sira I. Fuchs' heterochromic iridocylitis: an electron microscopic study of the iris. Invest Ophthalmol Vis Sci 1978;17: 1193-9.

20. Berger BB, Tessler HH, Kottow MH. Anterior segment ischemia in Fuchs' heterochromic cyclitis. Arch Ophthalmol 1980;98:499-501.

21. Saari M, Vourre I, Nieminen H. Fuchs' heterochromic cyclitis: a simultaneous bilateral fluorescein angiographic study of the iris. Br J Ophthalmol 1978;62:715-21.

22. De Abreu ML, Belfort R, Hirata PS. Fuchs' heterochromic cyclitis and ocular toxoplasmosis. Am J Ophthalmol 1982;93:739-44.

23. Arffa RC, Schlaegel TF. Chorioretinal scars in Fuchs' heterochromic iridocyclitis. Arch Ophthalmol 1984;102: 1153-5.

24. Saraux H, Laroche L, Le Hoang P. Secondary Fuchs' heterochromic cyclitis: a new approach to an old disease. Ophthalmology 1985;190:193-8.

25. Vourre I, Saari M, Tilikainen A, Rasanen O. Fuchs' heterochromic cyclitis associated with retinitis pigmentosa: a family study. Can J Ophthalmol 1979;14:10-6.

26. Donoso LA, Eiferman RA, Magargal LE. Fuchs' heterochromic cyclitis associated with subclavian steal syndrome. Ann Ophthalmol 1981;13:1153-5.

27. Murray PI, Mooy CM, Visser-de Jong E, Baarsma GS, de Vries J, de Jong PTVM, Kijlstra A. Immunohistochemical analysis of iris biopsy specimens from patients with Fuchs' heterochromic cyclitis. Am J Ophthalmol 1990;109:394-9.

28. La Hey E, Mooy CM, Baarsma GS, de Vries J, de Jong PTVM, Kijlstra A. Immune deposits in iris biopsies from patients with Fuchs' heterochromic iridocyclitis. Am J Ophthalmol 1992;113:75-80. 